\title{
Stress and the Periodontium
}

Nisha Sharma, Sheela Kumar Gujjari, Sachin Kanagotagi

\begin{abstract}
Stress or tension is an unavoidable part of human life. It has been proven to cause not only health-related problems but problems pertaining to periodontium too. These include periodontal pocket formation, apical migration of junctional epithelium and delated wound healing. This paper connects the link between stress, its effect on general health and consequently on oral health.
\end{abstract}

Keywords: Stress, Immunomodulatory response, Hypothalamopituitary axis, Eustress, Distress.

How to cite this article: Sharma N, Gujjari SK, Kanagotagi S. Stress and the Periodontium. J Contemp Dent 2012;2(2):28-30.

Source of support: Nil

Conflict of interest: None declared

\section{INTRODUCTION}

The relationship of sound mind to the maintenance of a healthy body has been recognized throughout most of recorded history from the time of ancient Romans, Greeks and Chinese. ${ }^{1}$ Hans Seyle was largely responsible for giving the term stress its current saliency. Seyle defined stress as a response state of the organism to forces acting simultaneously on the body which if excessive, that is straining the capacity of adaptive process beyond their limits, lead to disease of exhaustion and death. In simple words it can be considered as physiological response of the organism to a perceived challenge or threat. ${ }^{1,20}$

Stressors are forces that have the potential to challenge the adaptive capacity of the organism. The group of stressors could be either mental/psychosocial or physical. These stressors either lead to eustress or distress, which are body's adaptive response to restore homeostasis. Distress meansa negative coping mechanism in which a person feels so pressurized with a situation that he tries alternative methods of evasion or avoidance and indulges into habits likesmoking, nail bitting, etc. Eustress means positive coping with however difficult situation may arise., ${ }^{2,18}$

The various stressors can be classified as follows: ${ }^{23}$

1. Job-related factors: Leading to absenteeism, altered performance, tardiness.

2. External/non-job-related factors: Family relationships, excessive commuting time and distance, economic factors, high interest rates, demands placed on an individual by a community and social activity.

3. Individual or personal characteristics: This includes:

- Type A personalities: Excessive aggressiveness, time urgency, restlessness, hostility and tenseness
- Type B personalities: Calm behavior

- Internals: Those who believe that their lives are their own responsibility and for most part under their personal control

- Externals: Those individuals who believe that control of their life is basically external to them; some one else or fate controls what happens to them.

Type A personalities have higher amount of psychological stress and found to be behind schedule always. Individuals who score as externals experience high stress than internals on locus of control scale. Stress is also higher in individuals who do not exercise, who have low self-esteem, who have low tolerance to change, poor dietary habits, excessive weight and smoking., ${ }^{3,15}$

The individuals reaction to stress is termed as coping refers to a person's efforts through action and thought to deal with demands perceived as taxing or overwhelming. ${ }^{4}$ Responses of the body include: ${ }^{5,23}$

1. Endocrine response

2. Immunomodulatory response

3. Acute phase reaction

\section{Endocrinal Response}

The hypothalamo-pituitary adrenal axis and sympathoadrenal medullary system come into play.,19

Both these systems act on adrenal cortex and medulla and help in release of insulin, androgens, thyroid hormones, cortisol, catecholamines, etc. leading to protein degradation, increased glucose synthesis, lypolytic action, sodium retension, inhibition of new bone formation leading to osteoporosis and tetany. Can also cause eosinopenia, lymphopenia, basopenia, neutrophilopenia, thrombocytosis and decreased clotting time.,

\section{Immunomodulatory}

Substance-p, a neurotransmitter appears to transmit pain signals, cause vasodilation and increased blood flow to gingival and periodontal capillaries. Stimulate most immune cells via specific receptors, enhance the phagocytic activity of leukocytes and macrophages and stimulate T-cell proliferation and antibody production from B cells. ${ }^{7,20}$

\section{Acute Phase Reactants}

Acute phase reactants refer to physiological and metabolic alterations that ensure immediately after onset of infection or tissue injury namely, C-reactive proteins (CRPs), 
haptoglobin, hemopexin, fibrinogen, etc. whenever there is severe acute infection the liver gets stimulated to release them. Increased proinflammatory cytokines and inflammatory mediators-IL-1, 6 lead to elevated level of CRPs, alpha-2 macroglobulin and alpha-1 antitrypsin in gingival cervicular fluid (GCF). ${ }^{8,9}$

\section{CORRELATION OF THE BODY'S RESPONSE TO STRESS AND THE PERIODONTIUM}

Increased cytokines and acute phase reactants in GCF are pure indicators of stress and also correlate with alveolar bone loss score. ${ }^{10,11}$ Hence, acute phase reactants in GCF may be a useful biomarker of periodontitis contributing to systemic disease (Fig. 1). ${ }^{12,16}$

\section{Periodontal Considerations}

Stress distress and coping, behavior are important risk indicators for periodontal disease and common pathway for several chronic diseases in man (Fig. 2) ${ }^{13,18}$ These include neglect of oral hygiene, dietary inadequacies, poor sleep patterns, use of tobacco products:

1. Advanced periodontal inflammation

2. Aggressive periodontitis

3. Cardiovascular disease, diabetes mellitus, osteoporosis, preterm delivery, periodontal disease

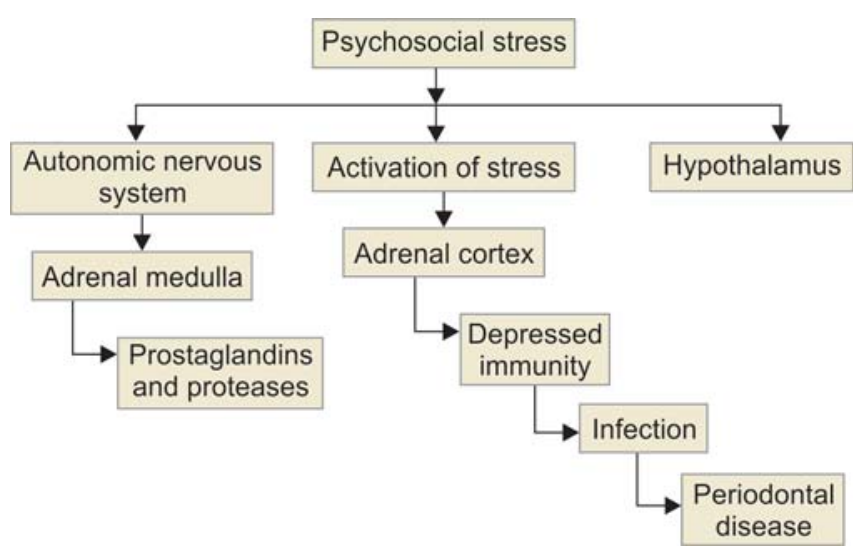

Fig. 1: Link between stress and the periodontium

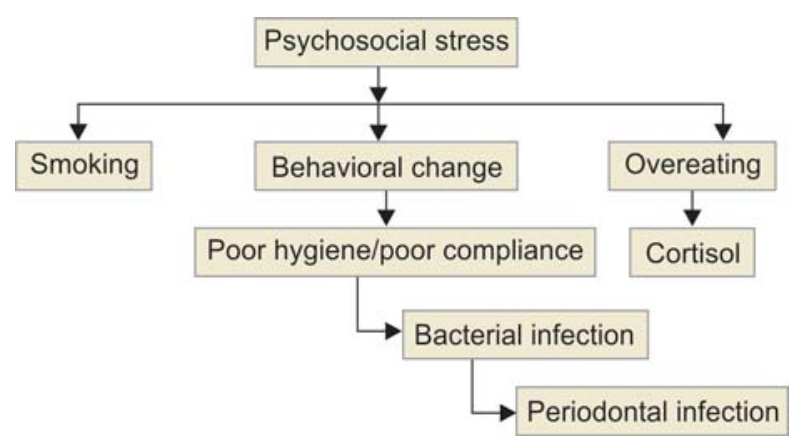

Fig. 2: Psychological stress mechanism and its outcome
4. Uncontrolled destruction in diabetes-associated periodontitis

5. Anug

Stress can also be hypothesized as common pathway for several chronic diseases of man (Fig. 3). ${ }^{10,20}$

\section{TOOLS FOR MEASUREMENT OF COPING WITH STRESS}

1. Sign and symptom-related general physical examination: Blood pressure, skin response, pulse, skin temperature, various endocrine responses

2. Various questionnaires-Stanford acute stress reaction questionnaire

3. DSM-IV dissociation disorders

4. Impact of event scale

5. Post-traumatic stress disorder (PTSD) symptom scale

6. Dissociative experience scale

7. Life events scale by savoia

8. Stress verarbatim fragebogan (SVF) scale $\mathrm{e}^{14,15,21,23}$

\section{PREVENTIVE MEASURES}

1. Anticipation of disaster in high-risk areas ${ }^{16,18}$

2. Disaster management

3. Positive coping strategies

\section{TREATMENT}

1. Careful history needs to be taken for checking any underlying stress or psychological disorder. ${ }^{22,23}$

2. Patient should be referred to a psychiatrist before commencing of the dental treatment.

Four basic approaches of dealing with stress: ${ }^{16}$

1. Removal or alteration of the source of stress

2. Learning to change way of perceiving stressful events

3. Reducing the effect of stress on the body

4. Learning alternative ways of coping-Proactive coping: Dealing with stress in advance

5. Jacobson's progressive muscle relaxation (JPMR $)^{17}$

6. Breathing exercises/meditation

7. Guided imagery

8. Drug therapy-Antidepressants and benzodiazepines ${ }^{21}$

9. Supportive psychotherapy.

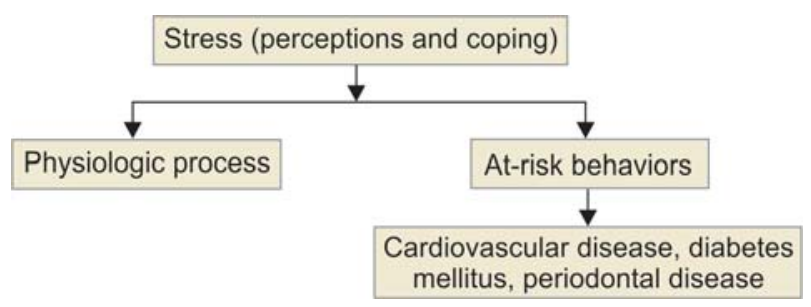

Fig. 3: Stress as common pathway for several diseases of man 


\section{CONCLUSION}

Acute stress has been associated with delayed healing of the connective tissues and bone in artificially induced gingival wounds. It has no effect on the epithelium. ${ }^{19}$ Chronic stress is associated with osteoporosis of alveolar bone, apical migration of the junctional epithelium and formation of periodontal pockets. ${ }^{23}$ It is important to recognize patient who are in stress and to be able to advise patients about the possible effects of stress on periodontal disease if the level of stress cannot be lowered. In addition all other risk factors for periodontal disease should be minimized, promoting good oral hygiene and smoking cessation. ${ }^{20}$ To live tension free it is very important that a person has a very positive stress coping style, and turns distress into eustress. Meditation and positive stress coping strategies can be best remedies for general and oral health. ${ }^{22,23}$

\section{REFERENCES}

1. Chrousos GP, Gold PW. The concepts of stress and stress system disorders. Overview of physical and behavioural hemostasis. J Am Med Assoc 1992;267:1244-52.

2. Chrousos GP, Gold PW. Stress, chronic inflammation, and emotional and physical well-being, concurrent effects and chronic sequalae. J Allergy Clin Immunol 2000;106: S275-S91.

3. Chrousos GP, Gold PW. A healthy body in a healthy mind- and vice-versa. The damaging power of uncontrollable stress. J Clin Endocrinol Metab 2002,83;1842-45.

4. Kiecolt-Glaser JK, Glaser R. Psychoneuroimmunology and health consequences: Data and shared mechanisms. Psychosom Med 1995;57:269-74.

5. Kiecolt-Glaser JK, McGuire L, Robles TF, Glaser R. Psychoneuroimmunology and psychosomatic medicine: Back to the future. Psychosom Med 2002;64:15-28.

6. Monroe SM. Major and minor life events as predictors of psychological distress. Further issues and findings. J Behav Med 1983;6:189-205.

7. LeResche L, Dworkin SF. The role of stress in inflammatory disease, including periodontal disease: Review of concepts and current findings. Periodontology 2002;30:91-103.

8. Monteiro da Silva AM, Newman HN, Oakley DA. Psychosocial factors in inflammatory periodontal diseases. A review. J Clin Periodontol 1995;22:516-26.

9. Breivik T, Thrane PS, Murison R, Gjermo P. Emotional stress effects on immunity, gingivitis and periodontitis. Eur J Oral Sci 1996;104:327-34.

10. Genco RJ. Current view of risk factors for periodontal diseases. J Periodontol 1996;67:1041-49.

11. Baume RM, Croog SH, Nalbandian J. Pain perception, coping strategies, and stress management among periodontal patients with repeated surgeries. Percept Mot Skills 1995;80:327-34.
12. Deinzer R, Ruttermann S, Mobes O, Herforth A. Increase in gingival inflammation under academic stress. J Clin Periodontol 1998;25:431-33.

13. Deinzer R, Forster P, Fuck L, Herforth A, Stiller-Winkler R, Idel H. Increase of crevicular interleukin 1beta under academic stress at experimental gingivitis sites and at sites of perfect oral hygiene. J Clin Periodontol 1999;26:1-8.

14. Monteiro da Silva AM, Oakley DA, Newman HN. Psychosocial factors and adult onset rapidly progressive periodontitis. J Clin Periodontol 1996;23:789-94.

15. Moulton R, Ewen S, Thiemen W. Emotional factors in periodontal disease. Oral Surg Oral Med Oral Path 1952;5:833-60.

16. Shannon IL, Kilgore WG, O’Leary T. Stress as a predisposing factor in necrotizing ulcerative gingivitis. J Periodontol 1969;40: 240-42.

17. Clay C, Maupin, Bell WB. The relationship of 17-Hydroxycorticosteroid to ANUG. J Periodontol 1975;721:436.

18. Genco RJ. Financial stress linked to periodontal disease. J Am Dent Assoc 1995;126:1346.

19. Genco RJ, Ho AW, Grossi SG, Dunford RG, Tedesco LA. Relationship of stress, distress and inadequate coping behaviors to periodontal disease. J Periodontol 1999;70:711-23.

20. Monteiro da Silva AM, Newman HN, Oakley DA, O’Leary R. Psychosocial factors, dental plaque levels and smoking in periodontitis patients. J Clin Periodontol 1998;25:517-23.

21. Croucher R, Marcenes WS, Torres MC, Hughes F, Sheiham A. The relationship between life-events and periodontitis. A casecontrol study. J Clin Periodontol 1997;24:39-43.

22. Minneman MA, Cobb C, Soriano F, Burns S, Schuchman L. Relationships of personality traits and stress to gingival status or soft-tissue oral pathology: An exploratory study. J Public Health Dent 1995;55:22-27.

23. Axtelius B, Soderfeldt B, Nilsson A, Edwardsson S, Attstrom R. Therapy-resistant periodontitis. Psychosocial characteristics. J Clin Periodontol 1998;25:482-91.

\section{ABOUT THE AUTHORS}

\section{Nisha Sharma}

Senior Lecturer, Department of Periodontics, MGM Dental College and Hospital, Navi Mumbai, Maharashtra, India

\section{Sheela Kumar Gujjari}

Professor, Department of Periodontics, JSS Dental College and Hospital, Mysore, Karnataka, India

\section{Sachin Kanagotagi}

Senior Lecturer, Department of Periodontics, MGM Dental College and Hospital, Navi Mumbai, Maharashtra, India

\section{CORRESPONDING AUTHOR}

Senior lecturer, Department of Periodontics, Junction of NH-4 and Sion-Panvel Expressway, Sector-18, Kamothe, Navi Mumbai-410209 Maharashtra, India, e-mail: nshvys@gmail.com 